\title{
Predicted Steady State Volume of Distribution Normalized by Surface Area
}

National Cancer Institute

\section{Source}

National Cancer Institute. Predicted Steady State Volume of Distribution Normalized by

Surface Area. NCl Thesaurus. Code C102392.

The volume of distribution at steady state based on the predicted CLST for a substance administered by intravascular dosing divided by the surface area. 